\title{
Effective fermentation of sugarcane bagasse whole slurries using robust xylose-capable Saccharomyces cerevisiae
}

\author{
Thapelo Mokomele ${ }^{1}$, Bianca Brandt ${ }^{1}$, and Johann Görgens ${ }^{1}$ \\ ${ }^{1}$ Stellenbosch University
}

October 2, 2021

\begin{abstract}
The pre-treatment of lignocellulose material toward cellulosic bioethanol production releases microbial inhibitors that severely limit the fermentation ability of Saccharomyces cerevisiae. This study evaluated to what degree robust xylose capable strains may improve the fermentability of non-detoxified sugarcane bagasse (SCB) slurries derived from steam explosion (StEX), and further compared this to slurries derived from ammonia fibre expansion (AFEX) pre-treatment. Initial screening in separate hydrolyses and co-fermentation processes using StEx-SCB hydrolysates identified S. cerevisiae TP-1 and CelluXTM4 with higher xylose consumption ([?] 88\%) and ethanol concentrations ([?] $50 \mathrm{~g} / \mathrm{L}$ ). Subsequent fermentations compared StEx and AFEX pre-treated SCB material under industrially relevant fed-batch pre-hydrolysis simultaneous saccharification and co-fermentation (PSSCF) conditions, which resulted in only $3 \mathrm{~g} / \mathrm{L}$ differences in ethanol titres for StEx and AFEX PSSCF fermentations. The study achieved non-detoxified whole-slurry co-fermentation using StEx pre-treated SCB, with higher ethanol yields than previously reported, by utilising robust xylose-capable strains.
\end{abstract}

\section{Hosted file}

Manuscript.docx available at https://authorea.com/users/439075/articles/540123-effectivefermentation-of-sugarcane-bagasse-whole-slurries-using-robust-xylose-capablesaccharomyces-cerevisiae

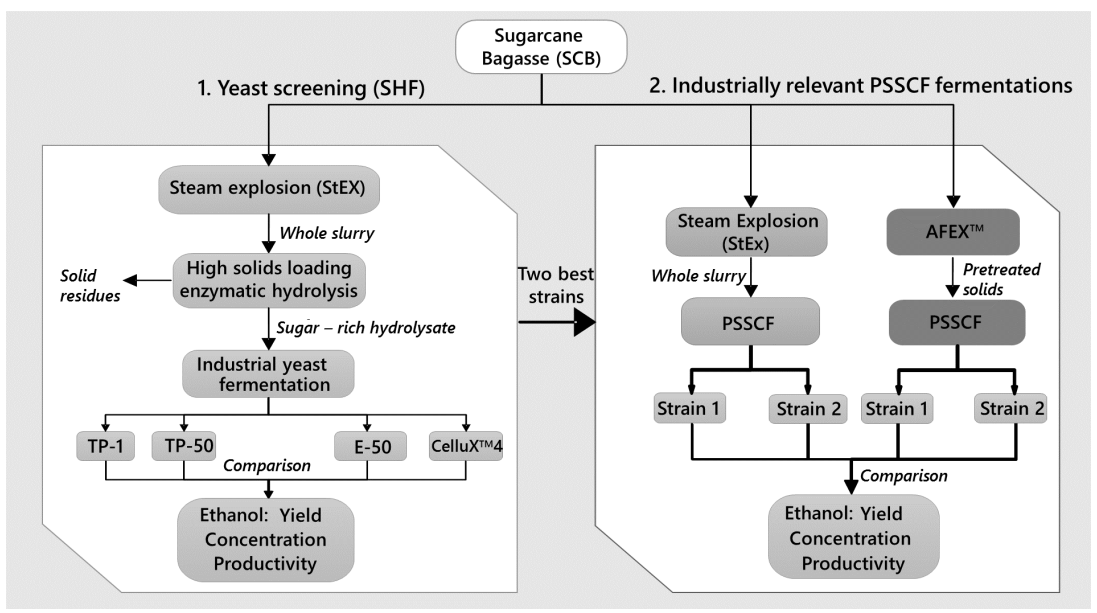



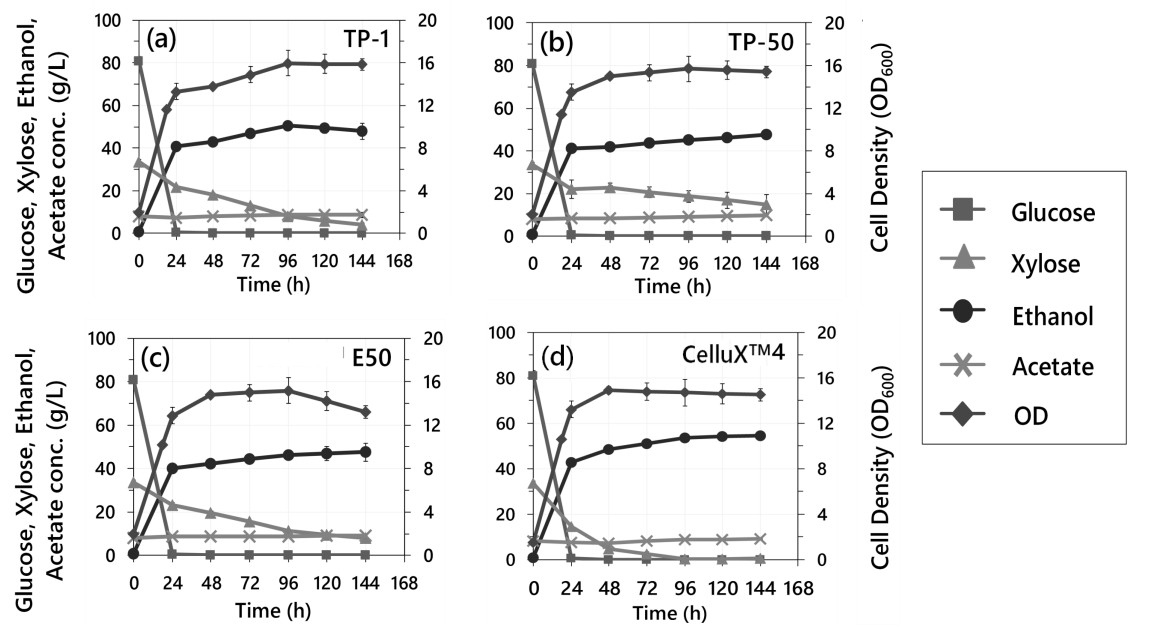

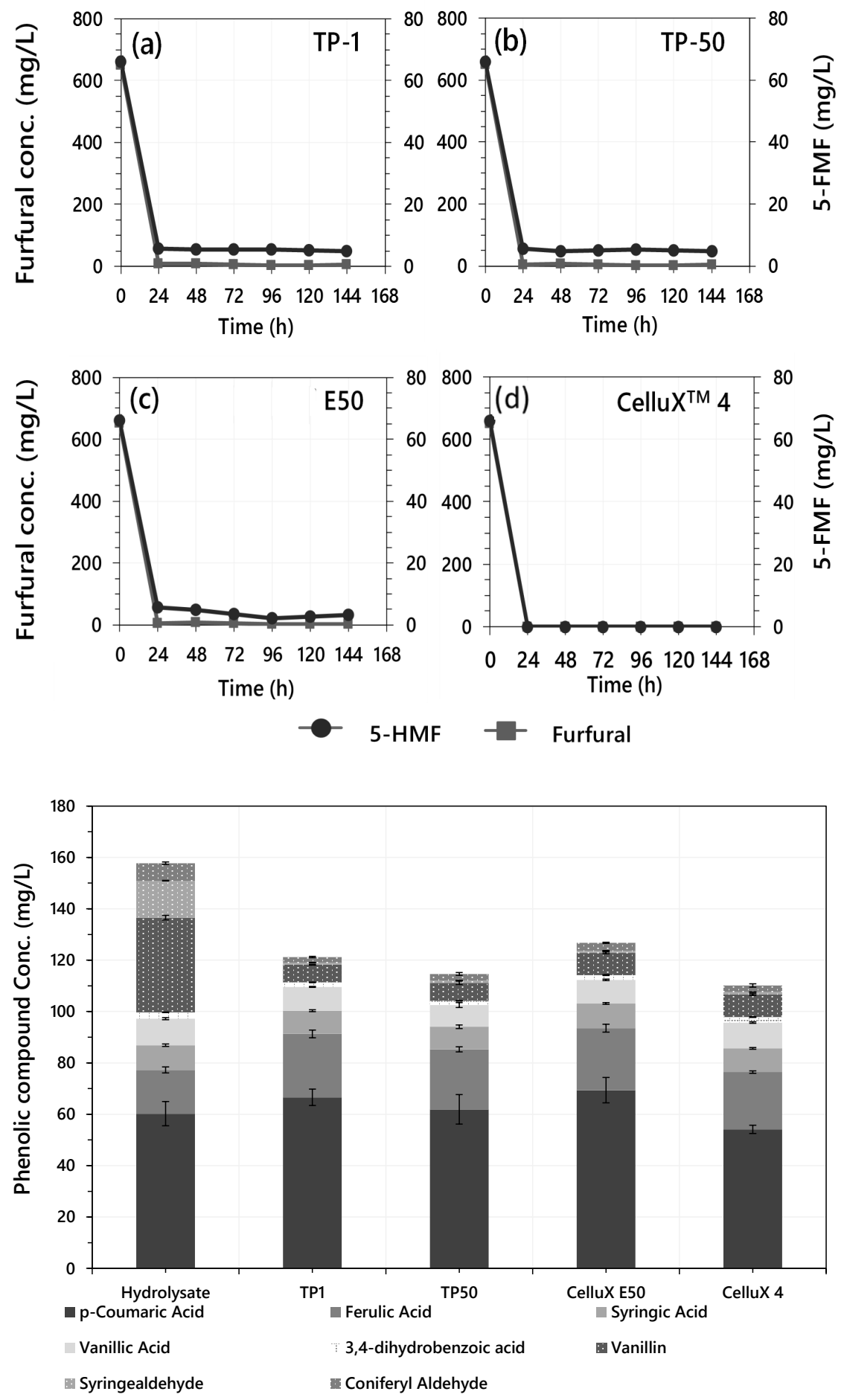

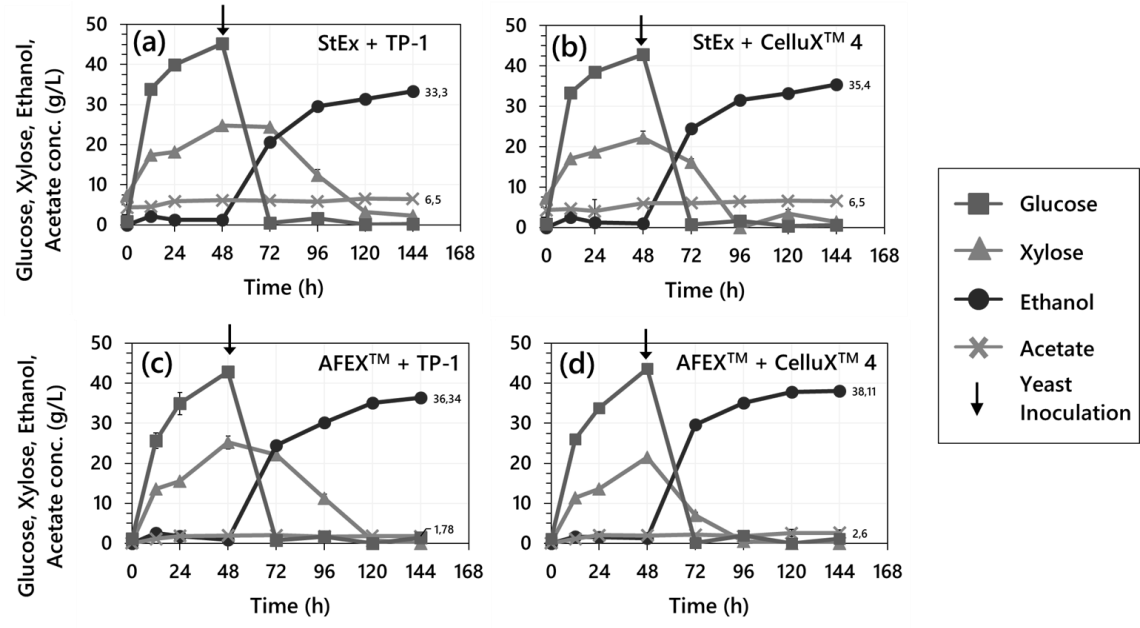


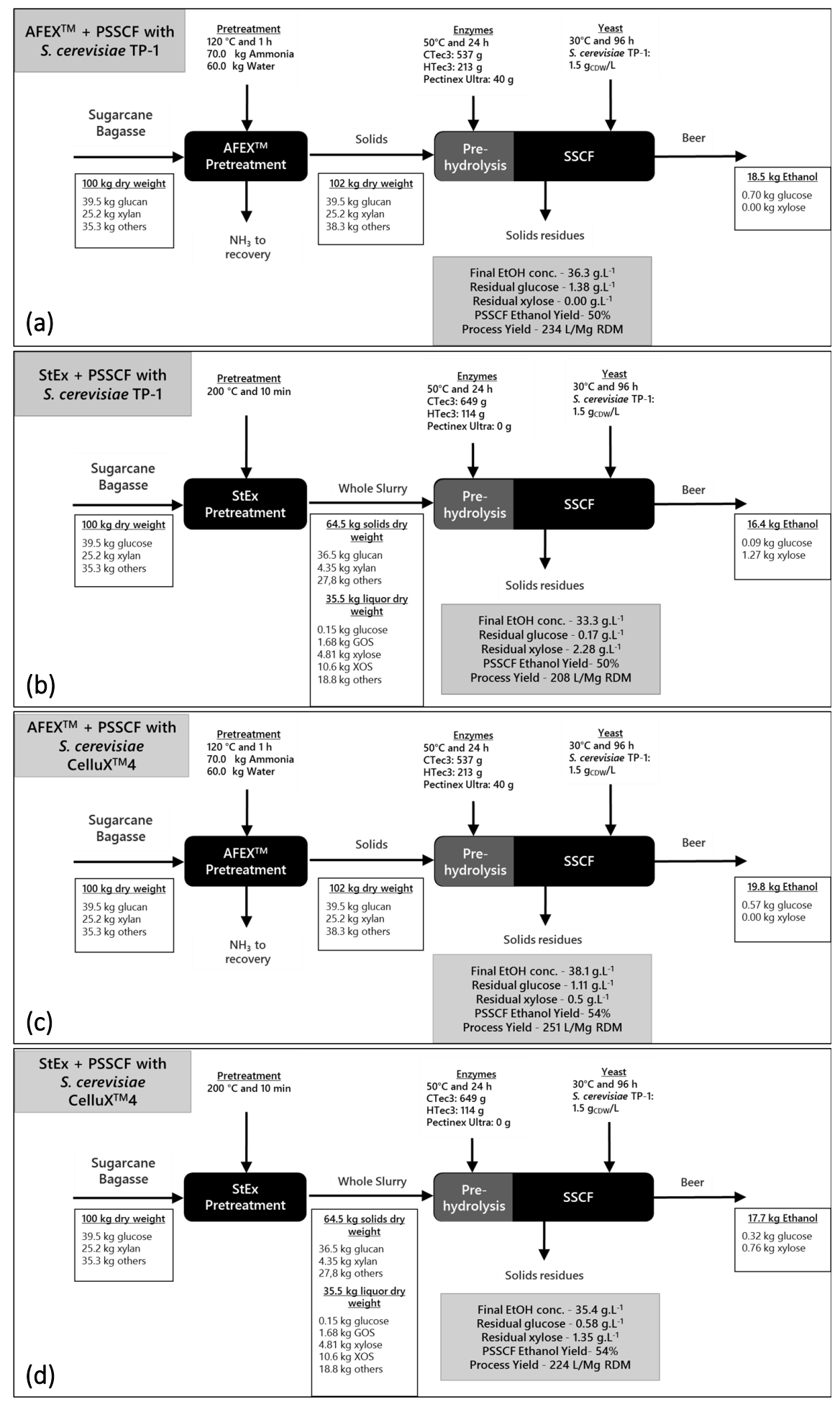

